Marilia Sá Carvalho 1

Oswaldo Gonçalves Cruz 2

Flávio Fonseca Nobre 3

\section{Perfil de risco: método multivariado de classificação sócio-econômica de microáreas urbanas - os setores censitários da região metropolitana do Rio de J aneiro}

\author{
Risk profile: multivariate cluster analysis \\ of urban small areas based on socioeconomic \\ indicators - census tracts from the Greater \\ Rio de J aneiro Metropolitan Area
}

1 Departamento de Epidemiologia, Escola Nacional de Saúde Pública, Fundação Oswaldo Cruz. Rua Leopoldo Bulhões 1480, Rio de Janeiro, RJ 21041-210, Brasil. marilia@malaria.procc. fiocruz.br

2 Programa de Computação Científica, Fundação Oswaldo Cruz, Residência Oficial,

Av. Brasil 4365, Rio de Janeiro, RJ, 21450-900, Brasil. oswaldo@malaria.procc. fiocruz.br

3 Programa de Engenharia Biomédica, Coordenação de Programas de Pós-Graduação em Engenharia, Universidade Federal do Rio de Janeiro. Centro de Tecnologia, Bloco H, Sala 327. C. P. 68510 , Cidade Universitária,

Rio de Janeiro, RJ 21945-970, Brasil. flavio@serv.peb.ufrj.br
Abstract A method based on small area data analysis was developed to build a health risk classification for the Greater Rio de Janeiro Metropolitan Area. The approach uses 1991 census data and studies data pertaining to sanitation, ownership and type of housing, size and occupancy of the household, demography, schooling, and income. Principal component analysis applied over each dimension allowed for the choice of 15 variables, which summarized most of the observed variances. Additional analysis with these variables suggested that just six variables are sufficient for the construction of a classification using k-means method of multivariate cluster analysis. Five classes were obtained: (A) high income; (B) lower income; (C) poor; (D) low schooling and income; (E) low-level access to sanitation. The existing inequality in each of the geopolitical established areas was clearly i dentified. The proposed method allowed for the construction of compound indices to evaluate quality of life, based on widespread and easily obtained data (the census). Moreover, the method contributed to the detection of socioeconomic inequality, identifying, not only the larger poor regions but also the small excluded areas.

Key words Demographic Census; Small-Area Analysis; Multivariate Analysis; Socioeconomic Analysis

Resumo Visando desenvolver métodos de estudo de mi croáreas urbanas, que permitam a integração de variáveis em um perfil sócio-econômi co, foi anal isado o censo demográfico de 1991, por setor censitário. Estudaram-se aspectos de: saneamento, ocupação do terreno, escolaridade, domi cílio, demografia e renda. A anál ise de componentes principais para cada tema permitiu selecionar 15 indicadores com maior poder de explicação da variância observada, com base nos quais, em nova análise, foram escol hi dos os sete indicadores finais. A classificação mul tivariada por partição gerou cinco ti pos diferentes de setores censitários, assim descritos: (A) alta renda, (B) renda mais baixa, (C) pobre, com predomínio de casas alugadas, (D) baixa escolaridade e renda, (E) precariedade no saneamento básico. A análi se segundo a divisão geopolítica tradicional permitiu identificar as desigual dades dentro de cada área. O método proposto permitiu a criação de índices compostos de aval iação de qualidade de vida, val endo-se de informações de fácil acesso e ampla cobertura. Além disso, contribuiu para detectar a desi gual dade sóci o-econômi ca, identi ficando não só as grandes regi ões de pobreza, mas as mi croáreas de exclusão em mei ò relativa riqueza.

Palavras-chave Censo Demográfico; Análise de Pequenas Áreas; Análise Multivariada; Perfil Sócio-econômico 


\section{Introdução}

O desenvolvimento de métodos que permitam a integração e análise de grande número de variáveis, tendo por objetivo a construção de um índice único, capaz de sintetizar os diferentes aspectos descritos univariadamente, é o propósito geral deste trabalho. Métodos de redução da dimensionalidade e de classificação multivariada foram aplicados a um conjunto de indicadores criados a partir de todas as variáveis do questionário básico do censo demográfico, visando à construção de um índice classificatório que pode ser tomado enquanto um perfil sócio-econômico, usualmente relacionado a risco diferenciado de adoecer ou morrer por diversos agravos. A identificação destes grupos populacionais é uma das questões-chave da prevenção em saúde, permitindo o direcionamento de medidas, sejam elas de cunho ambiental, educacional ou assistencial (Castellanos, 1990; Cortinovis et al., 1993; Verhasselt \& Mansourian, 1991).

Um aspecto importante na avaliação de risco diz respeito à metodologia de mensuração utilizada, à qual diferentes aspectos podem e devem ser incorporados, tais como medidas de atributos individuais, usualmente denominados fatores de risco, indicadores de ocorrência passada dos agravos em questão ou detecção de aspectos potencialmente danosos relacionados ao meio (Hayes, 1992). Em um contexto de avaliação de risco de grupos populacionais, a ênfase está nas doenças da população e não do indivíduo, a pergunta que se deseja responder não é sobre as causas dos casos de doença, mas sobre as causas da incidência da doença (Rose, 1985). Neste caso, duas questões sobressaem-se: a caracterização dos grupos sociais e o tratamento de diversos indicadores simultaneamente. A combinação de vários indicadores, os quais são medidas específicas que normalmente refletem apenas aspectos limitados da realidade, pode ser obtida através da criação de índices, que pretendem descrever de forma global determinado problema (Goldberg et al., 1979a;b).

Por outro lado, a caracterização sócio-econômica dos grupos populacionais, além de considerar todas as possíveis informações qualitativas - históricas, sociológicas, geopolíticas - pode ser abordada com base em informações amplamente acessíveis, como os indicadores do censo demográfico. Em que pesem seus limites quanto à qualidade, pertinência e oportunidade da informação, somente a ampla utilização das bases de dados secundários disponíveis permitirá aperfeiçoá-las.
As técnicas utilizadas na caracterização de perfis sócio-econômico foram a análise de componentes principais e método de classificação multivariado por partição, cujos conceitos básicos serão apresentados a seguir.

A análise de componentes principais é uma técnica multivariada utilizada para examinar, simultaneamente, a relação entre grande número de variáveis. Através da combinação linear das variáveis é possível calcular um conjunto de eixos não correlacionados (ortogonais), denominados autovetores, cada um dos quais capaz de representar parte da variância total do sistema. O primeiro componente é aquele que maximiza a variância total, o segundo maximiza o resíduo de variância entre as direções não correlacionadas ao primeiro e assim sucessivamente (Lebart et al., 1986). O peso relativo de cada variável na composição de cada eixo é medido através da sua correlação com este eixo. Desta forma, a análise de componentes principais pode ser utilizada como um instrumento de seleção de variáveis, na medida em que aquelas com maior peso na construção dos primeiros componentes, são as que possivelmente melhor representam o conjunto estudado.

A classificação multivariada, também denominada análise de cluster, é um conjunto de procedimentos que visa agrupar e discriminar grupos de indivíduos, regiões ou qualquer objeto. Estes agrupamentos ou cluster são constituídos definindo-se critérios baseados em distâncias. Distância é uma medida matemática de similaridade, que pode ser geográfica, temporal ou baseada em qualquer característica do objeto. Quando são utilizadas diversas variáveis é possível a construção de grupamentos onde o critério de similaridade está distribuído entre diversas características. Na construção dos conglomerados, o objetivo é que os objetos próximos - segundo a métrica selecionada - fiquem no mesmo grupo, enquanto as maiores distâncias separem grupos. Entre as medidas de similaridade, as mais freqüentes na literatura são: coeficientes de correlação, medidas de distância e coeficientes de associação.

Definida a métrica utilizada, diversos métodos de agrupamento podem ser empregados, hierárquicos e não hierárquicos. Os métodos hierárquicos podem ser ascendentes, nos quais o algoritmo de cálculo começa com tantos grupos quantos elementos e termina ao se reagrupar todo o conjunto, ou descendentes, em que o conjunto inicial de objetos vai sendo subdividido em aglomerados cada vez menores. O procedimento geral dos métodos não hierárquicos é a partição interativa em k grupos, utilizando 
critérios que diminuam a variância intragrupos e maximizem a variância intergrupos. O método não hierárquico k-means apresenta bom desempenho quando o número de grupos é pequeno em comparação com o número de elementos, tendo sido por isso selecionado para esta aplicação. Nos dois casos o objetivo é buscar que elementos semelhantes fiquem no mesmo grupo, e elementos diferentes fiquem em grupos distintos (Lebart et al., 1986).

Um aspecto importante nos trabal hos voltados para a caracterização de regiões é a extensão da base territorial de cada unidade geográfica, agregando grupos sociais distintos (favelas e áreas nobres), o que torna cada indicador selecionado média entre grupos populacionais diferentes. Evidentemente o acesso aos equipamentos urbanos, bem como os agravos à saúde não estão distribuídos homogeneamente na população. Entretanto, freqüentemente as informações necessárias não estão disponíveis no nível de agregação desejado. Raras são as informação microlocalizadas, e ainda mais raras as análises.

O censo demográfico, com todo um conjunto de informações gerais sobre a população, maior detalhamento sobre o chefe da família e características do domicílio, pode ser trabalhado em nível de microárea, uma vez que a unidade de agregação é o setor censitário, em média com novecentos habitantes. Neste trabaIho, os dados do censo de 1991 foram tratados, criando e identificando variáveis com maior capaci dade de expressar as diferenças intersetores, e utilizando-as em um processo de classificação multivariado que gerou uma tipolo- gia sócio-econômica dos setores censitários. Esta classificação e as variáveis selecionadas foram analisadas quanto à sua inserção na divisão administrativa usual da região, em Áreas Programáticas (APs) do Município do Rio de Janeiro e demais municípios da Região Metropolitana, utilizando o boxpl ot, técnica gráfica de análise exploratória de dados.

\section{Metodologia}

Dados

Foram utilizados os dados do censo de 1991, por setor censitário, disponibilizados pela Fundação IBGE em formato digital. A partir destas variáveis, foram criados diversos indicadores proporções e médias de ocorrência por setor censitário - agrupados em diversos blocos por tema analisado. Foi analisada a Região Metropolitana do Rio de Janeiro, (Figura 1) subdividida em três grupos para fins de comparação interna: Baixada Fluminense, Rio de Janeiro (capital) e demais municípios (Tabela 1).

Foi utilizada a divisão geopolítica em vigor no ano do censo (1991), segundo a qual a Região Metropolitana do Rio de Janeiro é composta por dez municípios. O Município do Rio de Janeiro (capital) foi analisado subdividido nas 24 Regiões Administrativas então existentes. Somente foram utilizados os dados do questionário global, uma vez que as informações relativas à amostra não permitem análise por microáreas. Todas as variáveis são a contagem do evento descrito no setor censitário.

Tabela 1

População e total de setores censitários¹ por município da Região Metropolitana do Rio de J aneiro, censo demográfico de 1991.

\begin{tabular}{|c|c|c|c|}
\hline Sub-região & Municípios & Setores censitários & População \\
\hline Rio (capital) & Rio de J aneiro & 6.258 & 5.480 .768 \\
\hline Baixada & Duque de Caxias & 599 & 667.821 \\
\hline Baixada & Nilópolis & 148 & 158.092 \\
\hline Baixada & Nova Iguaçu & 2.320 & 1.297 .704 \\
\hline Baixada & São J oão de Meriti & 353 & 425.772 \\
\hline Outros & Itaguaí & 190 & 162.742 \\
\hline O utros & Magé & 265 & 191.734 \\
\hline Outros & Maricá & 67 & 46.545 \\
\hline Outros & N iterói & 480 & 436.155 \\
\hline O utros & São Gonçalo & 676 & 779.832 \\
\hline Região Metropolitana & & 11.356 & 10.389 .441 \\
\hline
\end{tabular}

1 somente os setores censitários normais e subnormais, excluídos os coletivos. 


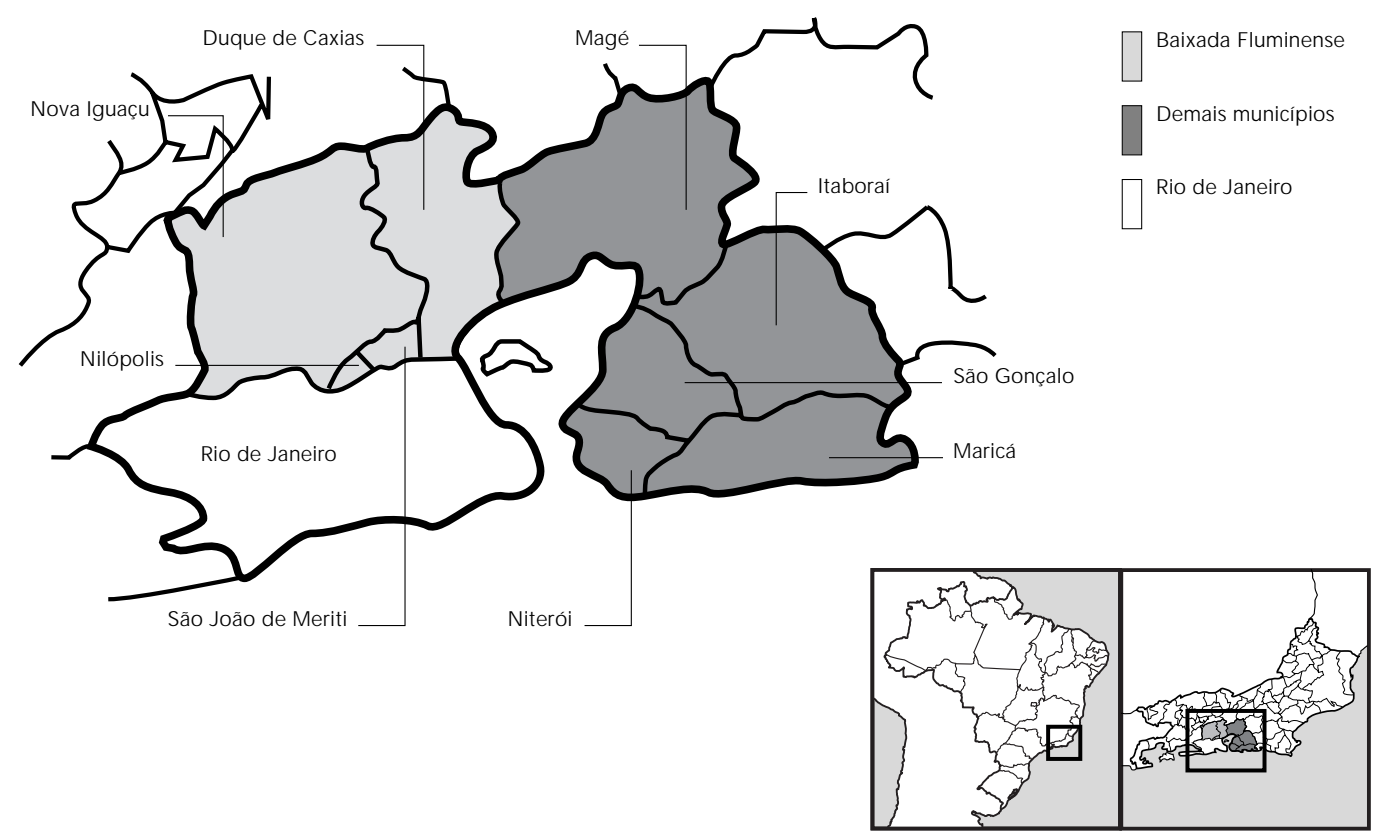

O questionário do censo divide-se em duas partes. A primeira dedicada ao domicílio e ao chefe da família, e a segunda dedicada a cada morador (FIBGE, 1994). Algumas definições das variáveis coletadas são necessárias visando esclarecer conceitos utilizados e melhorar a compreensão. Os setores censitários são classificados segundo a situação em urbanos e rurais. No Município do Rio de Janeiro todos os setores são considerados urbanos.

Quanto ao tipo, os setores podem ser:

Coletivos - Setores exclusivamente de habitações coletivas, como asilos, creches, quartéis, presídios e delegacias, que foram excluídos da análise, pois são em número reduzido e distorcem os indicadores, em função de sua feição especial.

Normais - Setores onde há estrutura urbana tradicional, com ruas, endereços, ainda que a propriedade do terreno eventualmente não seja bem definida.

Subnormais - A definição destes setores é pouco clara: “... conjunto constituído por unidades habitacionais ocupando ou tendo ocupado até período recente terrenos de propriedade alheia, dispostos, em geral, de forma desordenada edensa, e carentes, em sua maioria, de serviços públicos essenciais" (FIBGE, 1994).
Assim, em setores ditos 'normais', eventualmente podem ser encontrados domicílios precários, e, em setores considerados pelo censo 'subnormais', o tipo de moradia e situação de urbanização pode ser 'normal'. Para fins deste trabalho, consideraram-se os setores 'subnormais' como sendo favelas, fazendo-se a análise conjunta dos dois tipos.

Quanto às características do domicílio, a primeira subdivisão separa-os em particulares e coletivos e, entre os particulares, em permanentes e improvisados. A pesquisa das demais características dos domicílios limitou-se aos domicílios particulares permanentes, e pelo mesmo motivo os indicadores criados têm como denominador os domicílios particulares permanentes.

\section{Indicadores}

Na Tabela 2 são apresentados todos os indicadores criados, acrescentando-se, quando necessário, as explicações pertinentes. As proporções foram calculadas tomando-se como base o total de domicílios particulares permanentes. A utilização eventual de outros denominadores será devidamente explicada. Na coluna de observações do quadro de indicadores é referida 
a utilização de indicadores calculados pela própria FIBGE, e disponibilizados junto com os dados brutos. Algumas médias e medianas de variáveis contínuas foram também calculadas.

\section{Seleção dos indicadores}

Cada bloco de indicadores, exceto o demográfico devido à importância atribuída às quatro variáveis no perfil nosológico da população, foi submetido separadamente à análise de componentes principais. As duas ou três variáveis que apresentaram a maior contribuição na definição dos dois primeiros componentes foram selecionadas, sobrando desta primeira etapa da análise 11 variáveis, às quais se acrescentaram aquelas do bloco demográfico, totalizando 15. Estas foram submetidas em conjunto à nova análise de componentes principais, selecionando-se ao final os sete indicadores que meIhor representam o conjunto das variáveis analisadas. A variável Renda Média Nominal do Chefe da Família foi reescalonada para média 0 e desvio padrão 1.

A partir dos indicadores selecionados, o conjunto de setores censitários da Região Metropolitana do Rio de Janeiro foi submetido à análise classificatória multivariada pelo método k-means (Hartigan, 1975), resultando cinco diferentes perfis de classificação dos setores censitários.

\section{Resultados}

Os 15 indicadores selecionados inicialmente foram assinalados na Tabela 2 em negrito. A análise conjunta destes permitiu selecionar os sete indicadores utilizados na construção dos agrupamentos: proporção de domi cíli os alugados (CALUGA); proporção de casas (CASAS); proporção de domi cíl ios com água de rede pública (REDE); proporção de domicílios sem qualquer tipo de esgoto (SEMESG); proporção de população acima de cinco anos al fabetizada (ALFABET); proporção de chefes de família com escolaridadeigual ou maior queo segundo grau (2GRAU); renda médi a nominal do chefe da família (RNDCH).

Nenhum indicador demográfico foi utilizado na fase final de análise, pois com a inclusão de qualquer um deles o algoritmo empregado para a criação dos grupos não convergia. Isto é ocasionado pela forte relação entre estes indicadores e os indicadores de renda e escolaridade.

\section{Classificação multivariada}

A análise de cluster utilizando as sete variáveis selecionadas gerou cinco tipos diferentes de classes, descritas na Tabela 3, onde o valor de cada variável é a média das proporções da variável dentro de cada grupo.

O grupo de tipo " $A$ " apresenta o menor número de setores, apenas 190, e a maior renda (4,8 desvios-padrão acima da média). A proporção de residências de tipo casa é pequena, em média apenas 13\% dos domicílios. Os indicadores de escolaridade, especialmente a proporção de chefes de família com o segundo grau ou mais, diferenciam substancialmente este grupo dos demais.

A classe de setores de tipo " $B$ " diferencia-se da anterior essencialmente pela renda, que é $1 / 3$ da renda do grupo " $A$ ", embora 1,8 desviospadrão acima da média geral. Escolaridade do chefe da família acima do segundo grau é um pouco menos freqüente (75\%) e a proporção de residências alugadas aumenta de $18 \%$ para $26 \%$.

$\mathrm{O}$ agrupamento de tipo " $\mathrm{C}$ " pode ser caracterizado como um grupo mediano. A renda aproxima-se da média $(0,2)$, apenas $47 \%$ dos chefes de família têm escolaridade maior ou igual ao segundo grau. Nesta categoria concentra-se a maior parte das casas alugadas (32\%). Os grupos " $A$ ", “ $B$ " $\mathrm{e}$ " $C$ " somados atingem apenas 3.700 setores, ou seja, aproximadamente $33 \%$ do total.

Na caracterização do grupamento “D”, a baixa escolaridade do chefe da família (apenas $16 \%$ com segundo grau) e a maciça predominância de casas são fundamentais. A renda está ligeiramente abaixo da média global. Neste grupo, localizam-se mais de $50 \%$ dos setores da Região Metropolitana do Rio de Janeiro.

A categoria "E" apresenta a mais elevada proporção de analfabetos (33\%), 5\% dos domicílios particulares permanentes jogam esgotos na própria área da casa e apenas 16\% está ligado à rede pública de água. Nos dois últimos tipos diminui novamente a proporção de residências alugadas.

O perfil dos municípios da Região Metropolitana (Figura 2) apresenta três subgrupos nitidamente diferentes:

- Itaguaí, Magé, Maricá, os municípios mais afastados e rurais da Região Metropolitana: os setores censitários concentram-se nas classes "E" e "D", com poucos setores do tipo "C", nenhum setor de tipo " $B$ " ou " $A$ ", caracterizando os municípios como os de pior situação sócioeconômica segundo os indicadores escolhidos; - Caxias, Nilópolis, Nova I guaçu, São Gonçalo e São João de Meriti, com história semelhan- 
Tabela 2

Descrição dos principais indicadores por grupo temático, Censo Demográfico do IBGE, 1991*.

2A) Primeiro Bloco Temático - Estrutura e Inserção do Domicílio.

\begin{tabular}{|c|c|c|}
\hline Assunto & Indicador (proporção de) & Observações \\
\hline Residência & $\begin{array}{l}\text { domicílios improvisados } \\
\text { casas (construção unifamiliar) } \\
\text { apartamentos } \\
\text { casas de cômodos } \\
\text { domicílios coletivos } \\
\text { residências (casas+aptos) isoladas } \\
\text { residências em conjuntos populares } \\
\text { residências subnormais }\end{array}$ & $\begin{array}{l}\text { Estes indicadores têm como denominador o total de domicílios, } \\
\text { particulares ou coletivos, permanentes ou improvisados. }\end{array}$ \\
\hline Propriedade & $\begin{array}{l}\text { domicílios próprios em terreno próprio } \\
\text { construção própria e terreno não próprio } \\
\text { domicílios alugados } \\
\text { domicílios cedidos }\end{array}$ & $\begin{array}{l}\text { O denominador destes indicadores } \\
\text { é o total de domicílios particulares } \\
\text { permanentes. }\end{array}$ \\
\hline
\end{tabular}

* assinalados em negrito os indicadores selecionados após a primeira fase da análise.

2B) Segundo Bloco Temático - Saneamento.

\begin{tabular}{|c|c|c|}
\hline Assunto & Indicador (proporção de) & Observações \\
\hline Água & $\begin{array}{l}\text { domicílios com ligação interna } \\
\text { domicílios com água de rede pública } \\
\text { domicílios c/ ligação interna e rede pública } \\
\text { domicílios c/ ligação interna e s/ rede pública } \\
\text { domicílios s/ ligação interna e água } \\
\text { da rede pública } \\
\text { domicílios s/ ligação interna e s/ rede pública }\end{array}$ & $\begin{array}{l}\text { Denominador: total de domicílios particulares permanentes. } \\
\text { Indicadores combinando duas variáveis: } \\
\text { fonte da água e canalização interna. }\end{array}$ \\
\hline Esgoto & $\begin{array}{l}\text { domicílios c/ ligação à rede urbana de esgotos } \\
\text { domicílios com fossas } \\
\text { domicílios com outro tipo de esgotamento } \\
\text { domicílios sem qualquer tipo de esgotos }\end{array}$ & Denominador: total de domicílios particulares permanentes. \\
\hline Destino do lixo & $\begin{array}{l}\text { domicílios c/ coleta regular de lixo } \\
\text { domicílios onde o lixo é enterrado } \\
\text { domicílios onde o lixo é queimado } \\
\text { domicílios onde o lixo não recebe tratamento }\end{array}$ & Denominador: total de domicílios particulares permanentes. \\
\hline
\end{tabular}

2C) Terceiro Bloco Temático - Escolaridade.

\begin{tabular}{|c|c|c|}
\hline Assunto & Indicador (proporção de) & Observações \\
\hline Alfabetização & $\begin{array}{l}\text { mulheres acima de cinco anos alfabetizadas } \\
\text { homens acima de cinco anos alfabetizados } \\
\text { população acima de cinco anos alfabetizada } \\
\text { chefes de família mulheres alfabetizadas } \\
\text { chefes de família homens alfabetizados }\end{array}$ & Denominador: população acima de cinco anos. \\
\hline Escolaridade & $\begin{array}{l}\text { chefes de família c/ escolaridade < } 1 \text { ano } \\
\text { chefes de família c/ } 1 \text { - } 3 \text { anos de escolaridade } \\
\text { chefes de família c/ } 4-7 \text { anos de escolaridade } \\
\text { chefes de família c/ } 8 \text { - } 10 \text { anos de escolaridade } \\
\text { chefes de família c/ } 11 \text { - } 14 \text { anos de escolaridade } \\
\text { chefes de família c/ } 15 \text { e }+ \text { anos de escolaridade } \\
\text { chefes de família c/ segundo grau ou mais }\end{array}$ & $\begin{array}{l}\text { Denominador: chefes de domicílios particulares permanentes. } \\
\text { Utilizou-se também outros recortes para escolaridade. }\end{array}$ \\
\hline
\end{tabular}


2D) Q uarto Bloco Temático - Renda.

\begin{tabular}{|c|c|c|}
\hline Assunto & Indicador (proporção de) & Observações \\
\hline Renda do chefe & $\begin{array}{l}\text { renda média nominal dos chefes de família } \\
\text { chefes } \mathrm{c} / \text { renda até meio salário mínimo } \\
\text { chefes } \mathrm{c} / \text { renda de } 1 / 2 \text { a } 1 \text { salário mínimo } \\
\text { chefes } \mathrm{c} / \text { renda }>1 \text { a } 2 \text { salários mínimos } \\
\text { chefes } \mathrm{c} / \text { renda }>2 \text { a } 3 \text { salários mínimos } \\
\text { chefes } \mathrm{c} / \text { renda }>3 \text { a } 5 \text { salários mínimos } \\
\text { chefes } \mathrm{c} / \text { renda }>10 \text { a } 15 \text { salários mínimos } \\
\text { chefes } \mathrm{c} / \text { renda }>15 \text { a } 20 \text { salários mínimos } \\
\text { chefes } \mathrm{c} / \text { renda }>20 \text { salários mínimos }\end{array}$ & $\begin{array}{l}\text { Denominador: chefes em domicílios particulares permanentes. } \\
\text { O indicador renda média nominal do chefe é calculado } \\
\text { por setor censitário pelo IBGE. }\end{array}$ \\
\hline Empregados & média de empregados por domicílio & $\begin{array}{l}\text { Total de empregados do setor por total de domicílios } \\
\text { particulares permanentes. }\end{array}$ \\
\hline Cômodos & média de cômodos por domicílios & Indicador calculado pelo IBGE. \\
\hline
\end{tabular}

2E) Quinto Bloco Temático - Demografia.

\begin{tabular}{lll}
\hline Assunto & Indicador & Observações \\
\hline Estrutura etária & $\begin{array}{l}\text { mediana etária de mulheres } \\
\text { mediana etária de homens } \\
\text { Chefe da família }\end{array}$ & $\begin{array}{l}\text { A mediana é uma medida menos sensível à ocorrência } \\
\text { de valores extremos sendo preferível à média. }\end{array}$ \\
Densidade & média de habitantes por domicílio & Em relação ao total de domicílios particulares permanentes. \\
\hline
\end{tabular}

Tabela 3

Média de cada indicador segundo grupos de classificação.

\begin{tabular}{lrrrrrrrr}
\hline Grupo & Freq. & CALUGA & CASAS & REDE & SEMESG & ALFABET & 2GRAU & RNDCH \\
\hline "A" & 190 & 0,18329 & 0,13464 & 0,97737 & 0,00299 & 0,96397 & 0,83297 & 4,83466 \\
"B" & 1.116 & 0,25938 & 0,13867 & 0,98289 & 0,00227 & 0,97012 & 0,74714 & 1,84796 \\
"C" & 2.394 & 0,32246 & 0,34883 & 0,98886 & 0,00257 & 0,95148 & 0,47100 & 0,23293 \\
"D" & 6.240 & 0,22374 & 0,94178 & 0,95250 & 0,01865 & 0,86476 & 0,15866 & $-0,43645$ \\
"E" & 1.416 & 0,12028 & 0,98036 & 0,16639 & 0,05290 & 0,77013 & 0,06890 & $-0,57562$ \\
\hline
\end{tabular}

te e usualmente descritos como cidades-dormitório, apresentam maior proporção de setores do tipo "D", pequena proporção de setores do tipo "C" e parcela variável de setores do tipo "E". Em função da menor parcela de setores tipo “E”, pode-se subdividir este grupo, ficando Nilópolis e São João de Meriti como os mais homogêneos, onde mais de $90 \%$ dos setores estão classificados no grupo “D”;

- Niterói, capital do antigo Estado do Rio de Janeiro, com perfil inteiramente diferente dos demais, muito mais parecido com algumas regiões do Município do Rio de Janeiro.

O Figura 3 apresenta o perfil das APs do Município do Rio de Janeiro. A proporção de setores no grupo "E" é consideravel mente menor em relação a figura anterior. É interessante observar que o tipo de setor "A" aparece em duas APs: na 2, onde se localizam os bairros da zona sul da cidade, e na 4, composta pela Barra da Tijuca e Jacarepaguá, bairros de ocupação recente para onde vem se deslocando a classe 
Figura 2

Distribuição dos setores censitários segundo classificação multivariada, Municípios da Região Metropolitana do Rio de J aneiro, 1991.

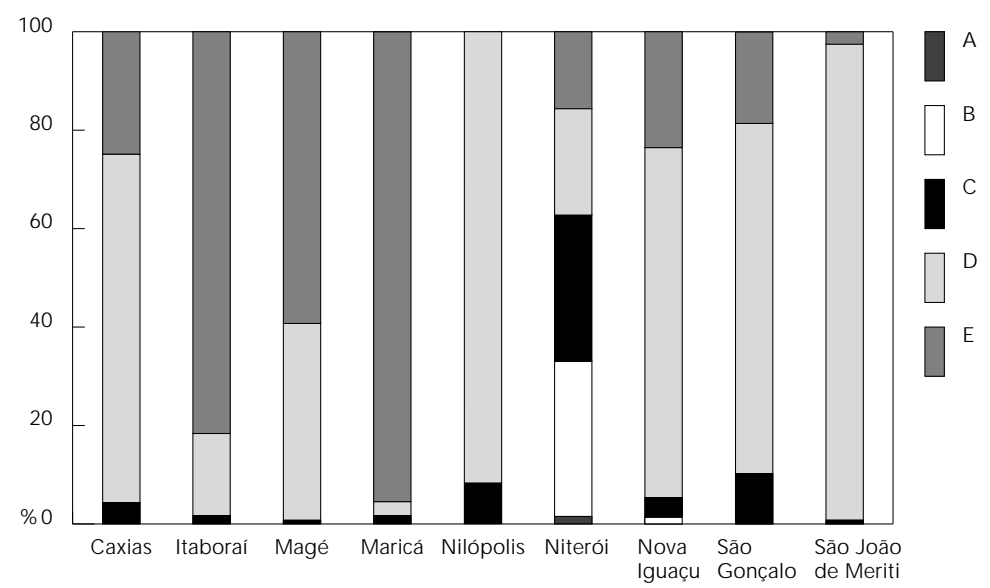

Figura 3

Distribuição dos setores censitários por grupo de classificação. Áreas programáticas do Município do Rio de J aneiro, 1991.

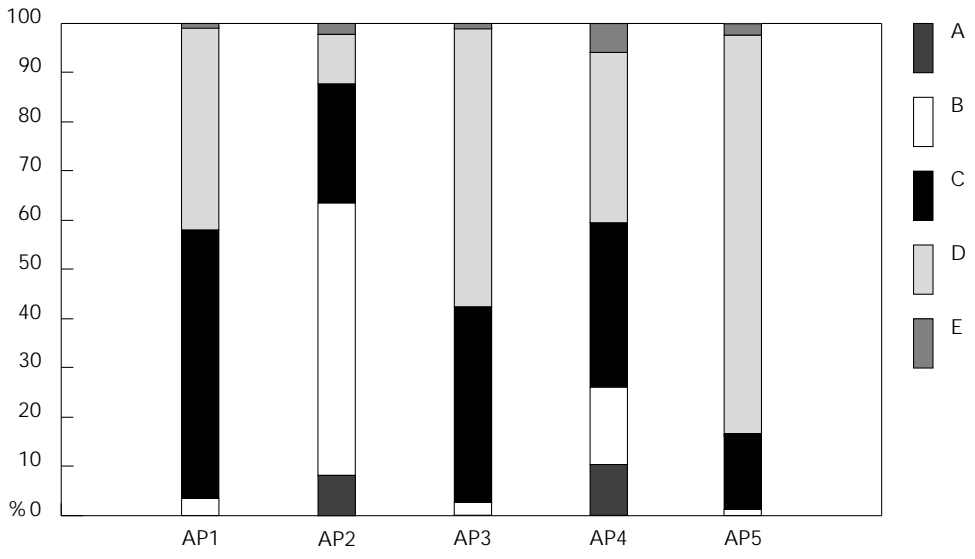

média e a população mais rica. Nestas APs também está presente o grupo " $B$ ", caracterizando-as como regiões efetivamente mais ricas. As APs 1 e 3, a primeira englobando as regiões do centro da cidade e a outra com os subúrbios tradicionais, apresentam perfil semeIhante, com a maior parte dos setores censitários concentrados nos grupos " $D$ " e "C $C$ ". A AP 5 - Zona Oeste - é a área de expansão recente para as populações de baixa renda, ainda relativamente desprovida dos serviços urbanos.

\section{Distribuição de indicadores selecionados}

As figuras apresentadas apenas indicam a proporção de setores de cada tipo segundo região. Para estudar a distribuição dos indicadores, optou-se por utilizar boxplots, tipo de figura que sumariza medidas robustas de tendência central e dispersão, onde o retângulo representa o intervalo interquartílico, a mediana apresentase ao meio na linha escura em destaque, a linha vertical pontilhada acima e abaixo dos quartis representa 1,5 vezes o intervalo entre a mediana e o respectivo quartil e os traços acima e abaixo destes valores representam outliers.

Em relação à proporção de residências com acesso à água da rede pública, o perfil dos municípios da Baixada Fluminense (Duque de Caxias, Nilópolis, Nova I guaçu e São João de Meriti) e demais municípios da Região Metropolitana é substancial mente diferente das APs do Rio de Janeiro (Figura 4). Nestas, a mediana da proporção de residências com acesso à água da rede pública entre os setores censitários é acima de $95 \%$, fazendo com que na figura fique ressaltada somente a presença de outliers. $\mathrm{O}$ acesso à água na Baixada e nos outros municípios da Região Metropolitana vai de 0 a 100\%, sendo a mediana mais baixa ( $90 \%)$ nestes. É interessante observar que na AP 2 é pequeno o número de setores com valores nos extremos da distribuição, mais freqüentes nas APs 4 e 5 . Ou seja, localizar espacialmente estes setores e direcionar medidas concretas pode ser factível, uma vez que são poucos, e a medida teria provavelmente impacto na saúde. Evidentemente o nível de investimento necessário no restante da Região Metropolitana é muito maior.

A distribuição do indicador proporção de domicílios sem qualquer tipo de esgoto é inversa à primeira, e ainda mais concentrada. Neste caso, a detecção e localização dos valores extremos permitirá concentrar medidas focais de saneamento. Por exemplo, apenas na AP 4 e na Baixada Fluminense existem setores censitários onde $100 \%$ das residências lançam esgotos no peridomicílio, sem qualquer tratamento ou remoção (Figura 5).

Da mesma forma, a análise dos valores aberrantes da Figura 6, proporção de população acima de cinco anos alfabetizada, permite localizar áreas problemáticas. Note-se que na AP 2 a maior parte da população é alfabetizada, enquanto nas demais áreas esta distribuição não é tão concentrada.

A escolaridade do chefe da família apresenta grandes diferenças entre as APs (Figura 7) quanto à mediana, destacando-se a AP 2 como a mais alta proporção de escolaridade igual ou 
mai or do que o segundo grau. Os setores censitários com valores extremos em cada região indicam a desigualdade da distribuição do indicador.

As duas últimas figuras apresentam a estrutura residencial quanto à propriedade e à forma de ocupação do espaço, por meio dos indicadores proporção de domicílios alugados (Figura 8) e proporção de casas (Figura 9). O primeiro apresenta a distribuição mais suave de todas, indicando que há variedade grande neste indicador dentro de cada setor censitário e, em cada sub-região, a parcela de residências alugadas não está concentrada exclusivamente em algumas áreas. No caso das APs 1, 3 e 4, em metade dos setores, cerca de $80 \%$ dos domicílios são casas, mas em diversos setores pequenas parcelas de apartamentos são encontrados. Cabe lembrar que classificados como apartamento estão os sobrados ou pequenos prédios de duas ou três moradias. No caso da AP 2, mais de $75 \%$ dos setores têm menos de $10 \%$ de casas, enquanto na Baixada, em mais de $75 \%$ dos setores, a proporção de casas é acima de $85 \%$.

\section{Comentários finais}

A análise realizada, utilizando as informações do censo demográfico por setor censitário, apresentou resultados interessantes em escalas diferentes. Em um nível mais macro, permitiu diferenciar facilmente cinco perfis sócioeconômicos na população da Região Metropolitana do Rio de Janeiro e apontou a grande diferença na composição dos municípios desta e APs da capital. Em escala maior, analisando por microárea, foi possível detectar os outliers, não apenas no sentido estatístico - localizados nos extremos da distribuição, mas no sentido também de marginal, à margem, excluído. Ou seja, embora no Município do Rio de Janeiro mais de $95 \%$ da população tenham acesso à rede de água, os setores censitários onde predominam casas sem este recurso são, evidentemente, as áreas mais carentes. Direcionar recursos para estas áreas terá, certamente, impacto no perfil de saúde da população.

Outras variáveis poderiam ser escolhidas, visando descrever a área segundo diferentes enfoques. A opção apresentada foi orientada pela perspectiva de analisar simultaneamente o conjunto, e, por isso, selecionaram-se indicadores menos correlacionados. Em alguns casos, quando duas variáveis apresentavam posicionamento semelhante na análise de componentes principais, optou-se por aquela que permitisse destacar situações excepcionais. É o
Figura 4

Boxplot da proporção de domicílios ligados à rede de água por Área Programática e Sub-regiões da Região Metropolitana do Rio de J aneiro, 1991.

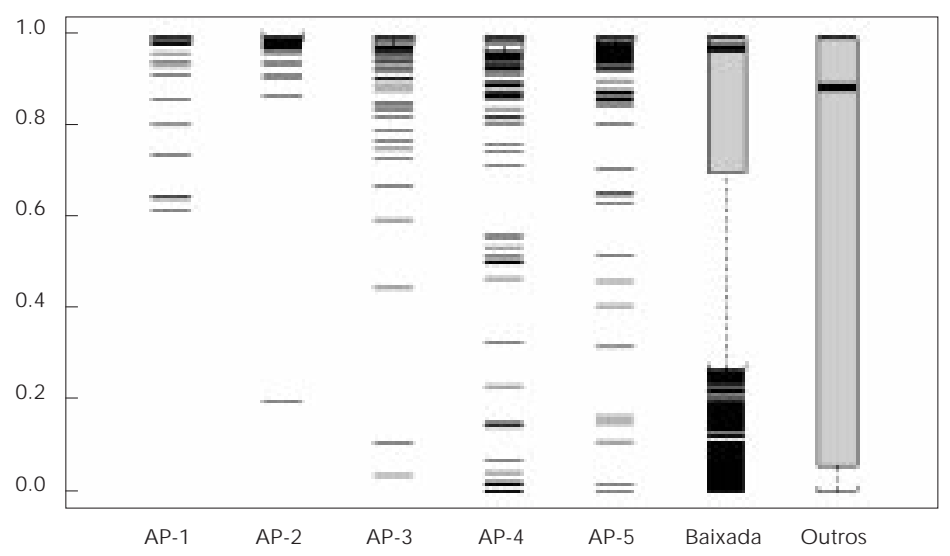

Figura 5

Boxplot da proporção de domicílios sem qualquer tipo de esgoto por Área Programática e Sub-regiões da Região Metropolitana do Rio de J aneiro, 1991.

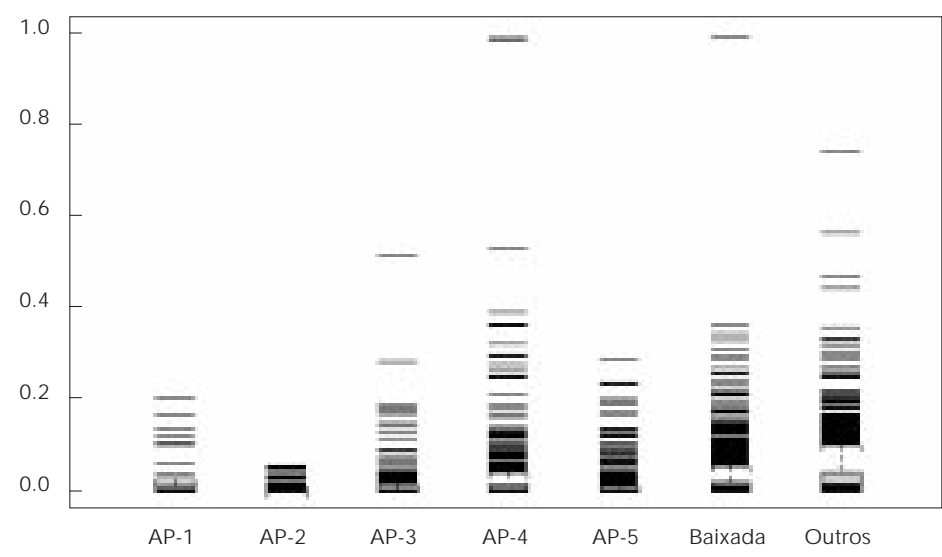

Figura 6

Boxplot da proporção de população alfabetizada por Área Programática e Sub-regiões da Região Metropolitana do Rio de J aneiro, 1991.

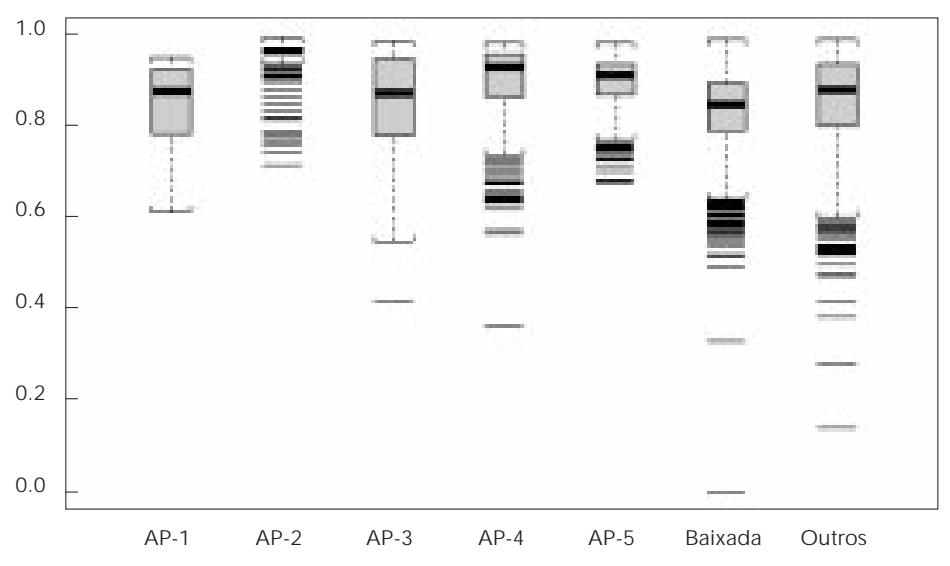




\section{Figura 7}

Boxplot da proporção de domicílios cujo chefe completou o 2 o grau por Área Programática e Sub-regiões da Região Metropolitana do Rio de J aneiro, 1991.

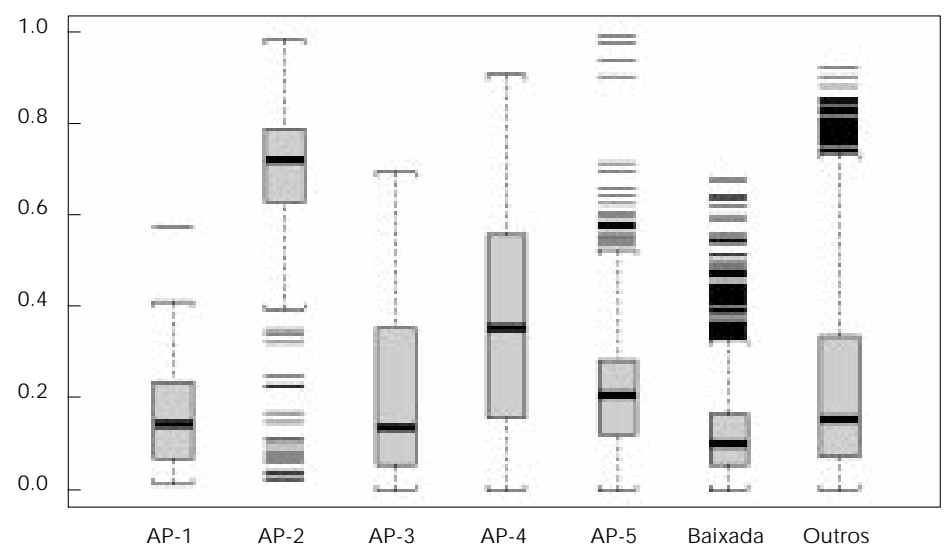

Figura 8

Boxplot da proporção de domicílios alugados por Área Programática e Sub-regiões da Região Metropolitana do Rio de J aneiro, 1991.

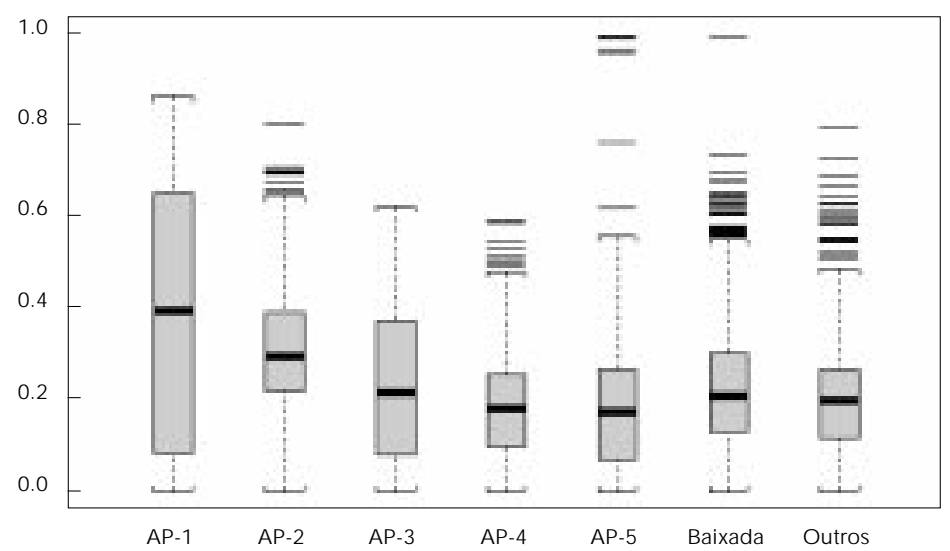

Figura 9

Boxplot da proporção de domicílios unifamiliares (casas) por Área Programática e Sub-regiões da Região Metropolitana do Rio de J aneiro, 1991.

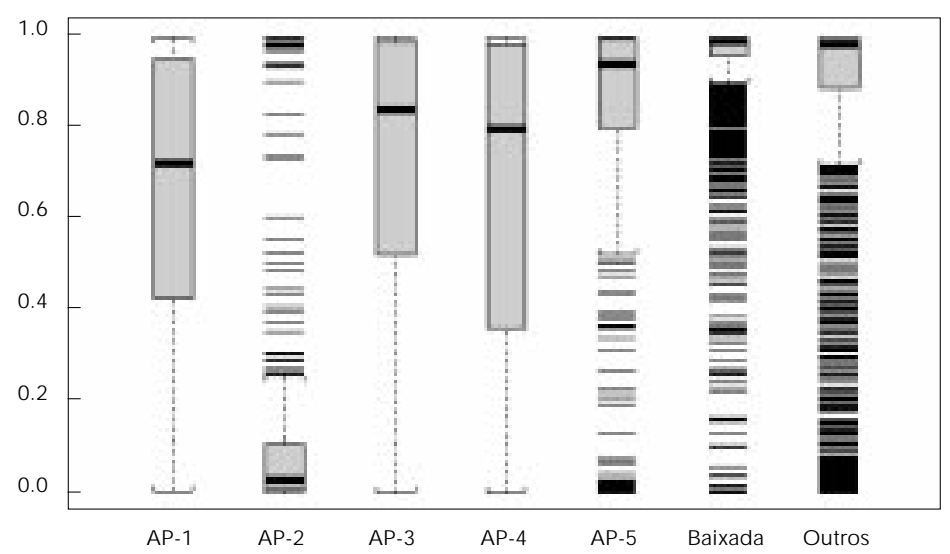

caso da variável proporção de domicílios sem qual quer tipo de esgoto, que caracteriza uma realidade pouco freqüente, porém de extrema gravidade. Outros indicadores disponíveis, como, por exemplo, a proporção de domicílios que lançam esgotos em valas negras, muito mais freqüentes, também poderiam ter sido utilizados, porém a variável escolhida detecta a situação 'marginal'.

O padrão espacial dos grupamentos sócio-econômicos existentes na região estudada apresenta características de mosaico, muito comum no Rio de Janeiro. Os setores censitários mais ricos situam-se ao lado de setores de excluídos. Ou seja, mesmo as áreas mais ricas, de mais alta renda, de moradores, por exemplo, da AP 2, apresentam setores censitários distribuídos por todas as classes, inclusive a "E". São mais homogêneas as regiões mais pobres, como os municípios de Itaguaí e Magé. Entretanto, seja morando no bairro rico, seja morando no subúrbio de baixa renda, grupos populacionais caracterizados no extremo inferior da escala aqui criada apresentam condições de vida igualmente precárias.

A classificação dos setores censitários foi feita para toda a Região Metropolitana do Rio de Janeiro, de forma a estabelecer comparação direta entre municípios e APs da capital. A mesma técnica, aplicada para regiões menores, permitiria maior discriminação interna (Carvalho et al., 1996). O mesmo tipo de técnica, aplicado em outras escalas geográficas - bai rro e municípios -, permitiu também a criação de perfis sócio-econômicos claramente definidos, corroborando a utilização deste tipo de técnica para estas variáveis. É interessante observar que foram poucas as alterações na seleção de variáveis, ainda que eventualmente tenha sido incluído ou retirado algum indicador (Cruz, 1996; D'Orsi, 1996).

Evidentemente os indicadores do censo apresentam diversos problemas, seja quanto à inexistência de informações relevantes, ou quanto à qualidade do dado. Entretanto, o método proposto é relativamente simples, parte de informações de fácil acesso e ampla cobertura, e permite uma primeira aproximação na criação de índices compostos de avaliação de qualidade de vida. Além disso, contribui para apontar a desigualdade na distribuição dos recursos, seja mapeando grandes regiões de pobreza, seja identificando microáreas de exclusão em meio à relativa riqueza. 


\section{Referências}

CARVALHO, M. S.; CRUZ, O. G. \& NOBRE, F. F., 1996. Spatial partition using multivariate cluster analysis and contiguity algorithm: application to Rio de Janeiro, Brazil. Statistics in Medicine, 15:1.8851.894.

CASTELLANOS, P. L., 1990. Sobre el concepto de salud-enfermedad. Descripción y explicación de la situación de salud. Boletin Epidemiológico, 10:1-7.

CORTINOVIS, I.; VELLA, V. \& NDIKU, J., 1993. Construction of a socio-economic index to facilitate analysis of health data in developing countries. Social Science and Medicine, 36:1.087-1.097.

CRUZ, O. G., 1996. Homicídios no Estado do Rio de Janeiro: Análise da Distribuição Espacial e sua Evolução. Dissertação de Mestrado, São Paulo: Faculdade de Saúde Pública, Universidade de São Paulo.

D'ÓRSI, E., 1996. Perfil de Nascimentos e Condições Sócio-Econômicas no Município do Rio dejaneiro: Uma Análise Espacial. Dissertação de Mestrado, Rio de Janeiro: Escola Nacional de Saúde Pública, Fundação Oswaldo Cruz.

FIBGE (Fundação Instituto Brasileiro de Geografia e Estatística), 1994. Censo Demográfico de 1991. Rio de Janeiro: FIBGE.
GOLDBERG, M.; DAB, W.; CHAPERON, J.; FULVIER, R. \& GRÉMY, F., 1979a. Indicateurs de santé et "sanométrie": les aspects conceptuels des recherches récentes sur la mesure de l'état de santé - première partie. Revue d'Épidémiologie et deSanté Publique, 27:51-68.

GOLDBERG, M.; DAB, W.; CHAPERON, J.; FULVIER, R. \& GRÉMY, F., 1979b. Indicateurs de santé et "sanométrie": les aspects conceptuels des recherches récentes sur la mesure de l'état de santé - seconde partie. Revue d'Épi démiologie et deSanté Publique, 27:133-152.

HARTIGAN, J. A., 1975. Clustering Algorithms. New York: John Wiley \& Sons Inc.

HAYES, M. V., 1992. On the epistemology of risk: Ianguage, logic and social science. Social Scienceand Medicine, 35:401-407.

LEBART, L.; MORINEAU, A. \& FÉNELON, J. P., 1986. Traitment de Données Statistiques - Méthodes et Programmes. Zème éd., Paris: Dunod.

ROSE, G., 1985. Indivíduos enfermos y poblaciones enfermas. Boletin Epidemiológico, 6:1-8.

VERHASSELT, Y. \& M ANSOURIAN, B., 1991. Método para la classificación de los países de acuerdo con sus indicadores de salud. Boletin de la Oficina Sanitária Panamericana, 110:319-323. 